УДК $669 \ldots 48$

\title{
Behavior of Components of Waste Solutions \\ of Precious Metals Refinery \\ in Autoclave Conditions
}

\author{
Natalya V. Belousova, Philipp A. Kylasov*, \\ Natalya V. Grizan and Dmitry A. Solokhov \\ Siberian Federal University \\ 79 Svobodny, Krasnoyarsk, 660041, Russia
}

Received 11.02.2015, received in revised form 30.03.2015, accepted 06.04.2015

Behavior of components of salt solutions with a low content of platinum grope metals $(<2 \mathrm{mg} / \mathrm{l})$ in hydrothermal conditions was investigated in this work. The changes of the phase composition and the precipitate characteristics were traced depending on the parameters of the hydrolytic precipitation of compounds of iron. Feasibilities of recovery of platinum grope metals from these solutions were discussed.

Keywords: autoclave technologies, iridium, iron salts, hydrolysis, precipitation of platinum group metals.

\section{Поведение компонентов растворов финишной очистки аффинажного производства \\ в автоклавных условиях}

Н.В. Белоусова, Ф.А. Кыласов, Н.В. Гризан, Д.А. Солохов Сибирский федеральный университет Россия, 660041, Красноярск, Свободньй, 79

В данной работе изучено поведение в гидротермальных условиях компонентов солевых растворов с низким содержанием металлов платиновой группь (< 2 мг/л каждого). Прослежено изменение состава фаз и характеристик осадка в зависимости от параметров гидролитического осаждения соединений железа. Рассмотрены возможности выделения металлов платиновой группы из данных растворов.

Ключевые слова: автоклавные технологии, иридий, соли железа, гидролиз, осаждение платиновых металлов.

(c) Siberian Federal University. All rights reserved

* Corresponding author E-mail address: kyulasov@ya.ru 
В настоящее время при разработке новых технологий металлургической переработки сырья, содержащего цветные металлы, и совершенствовании имеющихся технологических схем особое внимание уделяют вопросам наиболее полного извлечения ценных компонентов и, в частности, металлов платиновой группы (МПГ). Проблема заключается в том, что практически все технологические схемы (и пиро-, и гидрометаллургические), реализуемые на наших предприятиях, характеризуются наличием большого числа переделов, большим объемом незавершенного производства и ощутимыми суммарными потерями МПГ. Один из возможных вариантов совершенствования технологий предполагает использование автоклавов, которые позволяют не только интенсифицировать процессы, но и решить одновременно ряд экологических и экономических вопросов.

Цель данной работы - изучение поведения в гидротермальных условиях компонентов растворов с высоким солевым фоном, содержащих небольшие количества платиновых металлов (<2 мг/л каждого). Для экспериментов применяли автоклавы, конструкция которых описана в работах $[1,2]$.

Концентрации компонентов в растворе определяли атомно-адсорбционным методом, для изучения твердой фазы использовали рентгенофазовый анализ и просвечивающую электронную микроскопию.

Объектами исследований были растворы финишной очистки аффинажного производства, исходный состав которых представлен в табл. 1.

Как следует из приведенных данных, из металлов платиновой группы в самых больших количествах в растворе присутствует иридий. Этот металл хуже всего извлекается из растворов, что объясняется кинетической заторможенностью процессов с его участием. Количественное восстановление иридия до металлического состояния в нормальных условиях практически невозможно. Гидротермальные (автоклавные) условия позволяют интенсифицировать подобного рода процессы и снять кинетические ограничения.

Первый этап исследований предполагал нагревание растворов в автоклавах до заданных температур (383-453 К) без добавления осадителей. В процессе нагревания шло образование соединений железа с их последующим гидролизом, что фиксировалось визуально по появлению осадка, цвет которого в зависимости от условий (температуры и времени эксперимента) изменялся от желтого до красно-бурого.

Условия экспериментов и результаты представлены в табл. 2 и на рис. 1, 2 (ввиду близости значений на рис. 1 показана только часть полученных данных).

Из полученных данных следует, что увеличение температуры приводит к увеличению массы осадка и уменьшению значений $\mathrm{pH}$, т.е. к увеличению кислотности среды. Наибольшее изменение показателей осаждения при 453 К происходит в первые 90 мин.

Таблица 1. Состав солевых растворов, мг/л

\begin{tabular}{|c|c|c|c|c|c|c|c|c|c|c|c|}
\hline $\mathrm{Na}$ & $\mathrm{Fe}$ & $\mathrm{S}$ & $\mathrm{Mg}$ & $\mathrm{Cu}$ & $\mathrm{Cl}$ & $\mathrm{Ni}$ & $\mathrm{Zn}$ & $\mathrm{Se}$ & $\mathrm{Si}$ & $\mathrm{Ca}$ & $\mathrm{Mn}$ \\
\hline 6400 & 5900 & 860 & 670 & 100 & 51 & 47 & 46 & 41 & 26 & 26 & 17 \\
\hline $\mathrm{Al}$ & $\mathrm{K}$ & $\mathrm{Cd}$ & $\mathrm{Re}$ & $\mathrm{Co}$ & $\mathrm{As}$ & $\mathrm{Ag}$ & $\mathrm{Ir}$ & $\mathrm{Rh}$ & $\mathrm{Pt}$ & $\mathrm{Ru}$ & $\mathrm{Os}$ \\
\hline 13 & 13 & 13 & 4,5 & 1,6 & 0,63 & 2,1 & 1,8 & 0,6 & 0,11 & 0,1 & 0,078 \\
\hline
\end{tabular}


Таблица 2. Гидролитическое осаждение солей железа*

\begin{tabular}{|c|c|c|c|c|c|}
\hline $\begin{array}{l}\text { Материал } \\
\text { автоклава }\end{array}$ & Температура, К & Время, ч & Масса осадка, г & $\mathrm{pH}$ & $\mathrm{E}, \mathrm{MV}$ \\
\hline кварц & 373 & 2 & 0,047 & 1,6 & 396,1 \\
\hline PTFE & 383 & 0,5 & $\begin{array}{c}\text { Не } \\
\text { фиксировали }\end{array}$ & 1,49 & 397 \\
\hline PTFE & 383 & 1 & 0,092 & 1,65 & 423,5 \\
\hline PTFE & 383 & 1 & 0,055 & 1,56 & 422,2 \\
\hline PTFE & 383 & 2 & $\begin{array}{c}\text { Не } \\
\text { фиксировали }\end{array}$ & 1,22 & 370,6 \\
\hline PTFE & 383 & 4 & 0,01 & - & - \\
\hline кварц & 403 & 2 & 0,1 & 1,02 & 438,2 \\
\hline кварц & 423 & 0,5 & 0,046 & 1,09 & 408 \\
\hline PTFE & 423 & 1 & 0,087 & 1,04 & 406,7 \\
\hline кварц & 423 & 2 & 0,3 & 0,99 & 474,3 \\
\hline PTFE & 423 & 2 & 0,1 & 0,94 & 431 \\
\hline PTFE & 423 & 4 & $\begin{array}{c}\text { Не } \\
\text { фиксировали }\end{array}$ & 0,85 & 496,6 \\
\hline PTFE & 453 & 0,5 & $\begin{array}{c}\text { Не } \\
\text { фиксировали }\end{array}$ & 1,07 & 391,9 \\
\hline PTFE & 453 & 1 & 0,111 & 0,75 & 497 \\
\hline PTFE & 453 & 1 & 0,14 & 0,8 & 492,4 \\
\hline PTFE & 453 & 4 & 0,2 & 0,6 & 513 \\
\hline PTFE & 453 & 4 & 0,2 & 0,63 & 514,8 \\
\hline $\begin{array}{c}\text { * Исходный } \\
\text { раствор }\end{array}$ & 298 & - & - & 2,08 & 394,6 \\
\hline
\end{tabular}

Кроме того, можно отметить, что увеличение температуры сопровождается увеличением крупности осадка, что позволяет осуществлять разделение фаз даже декантацией. Это очень важный результат, свидетельствующий в пользу автоклавных технологий, поскольку одним из серьезных, осложняющих моментов гидрометаллургии является фильтрация растворов с мелкодисперсными осадками.

На рис. 3 и 4 представлены фотографии осадков, полученные методом электронной просвечивающей микроскопии. Осадок, сформировавшийся при 423 К, имел оранжевый цвет, а составлявшие его призматические кристаллы, согласно данным РФА, представляли собой гидроксохлорид железа.

Совсем иная картина наблюдается при 453 К: осадок имеет темно-коричневый цвет, образован частицами сферической и игольчатой формы (гематит и гетит).

Хотя считается, что соединения железа являются хорошими сорбентами металлов платиновой группы, анализ показал, что платиновые металлы на осадках не сорбировались.

После гидролитического осаждения железа содержание родия и иридия в растворе не меняется. Полученный вывод подтверждают данные полного растворения образующихся гидролитических осадков (благородные металлы не обнаружены).

$$
-516-
$$




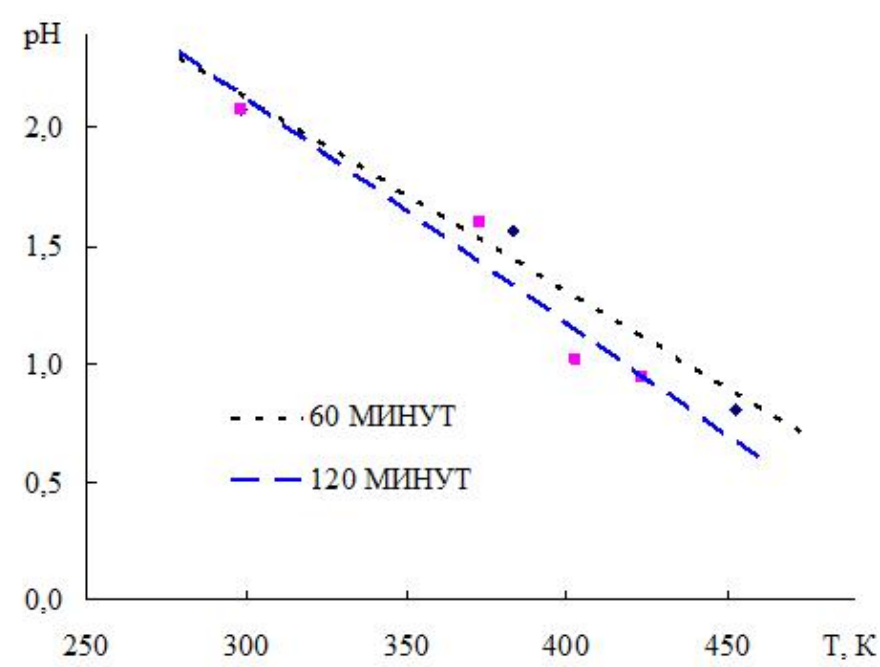

Рис. 1. Зависимость $\mathrm{pH}$ раствора от температуры

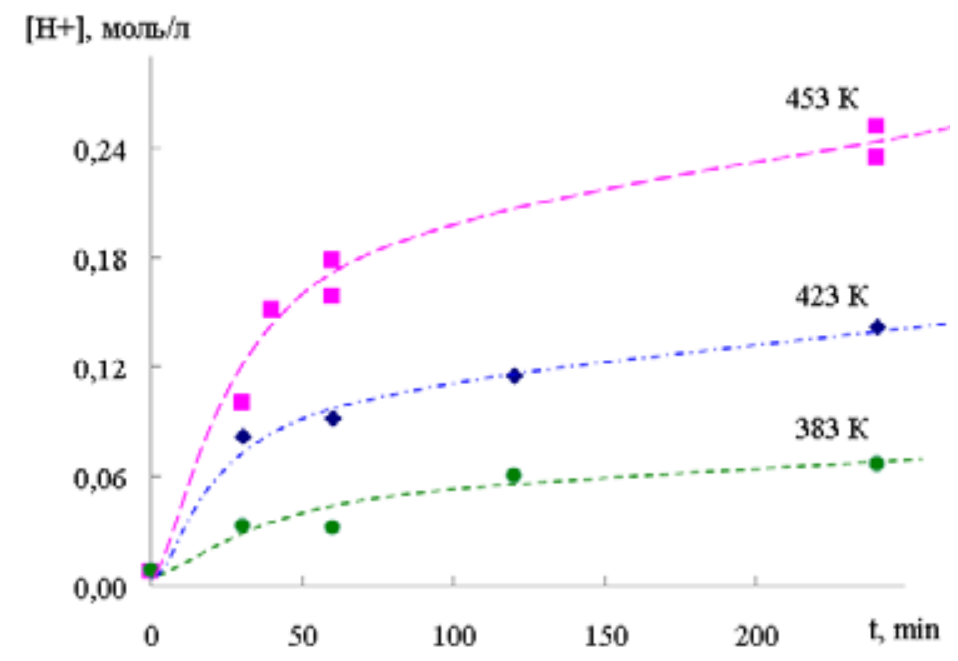

Рис. 2. Кинетические кривые изменения концентрации ионов водорода в процессе гидролиза

Осаждение иридия и родия из исходных растворов проводили сульфитом и тиосульфатом натрия. Результаты экспериментов представлены в табл. 3.

Они показывают, что тиосульфат натрия является более эффективным осадителем иридия, при этом увеличение времени осаждения с 4 до 8 ч не приводит к изменению степени осаждения иридия и родия.

На основании полученных данных можно сделать вывод, что принципиально глубокое обезблагораживание растворов с низкими концентрациями металлов платиновой группы возможно, но поиск оптимальных условий требует продолжения исследований как в направлении выбора осадителя, так и с точки зрения таких параметров осаждения, как концентрация осадителя и температура. 


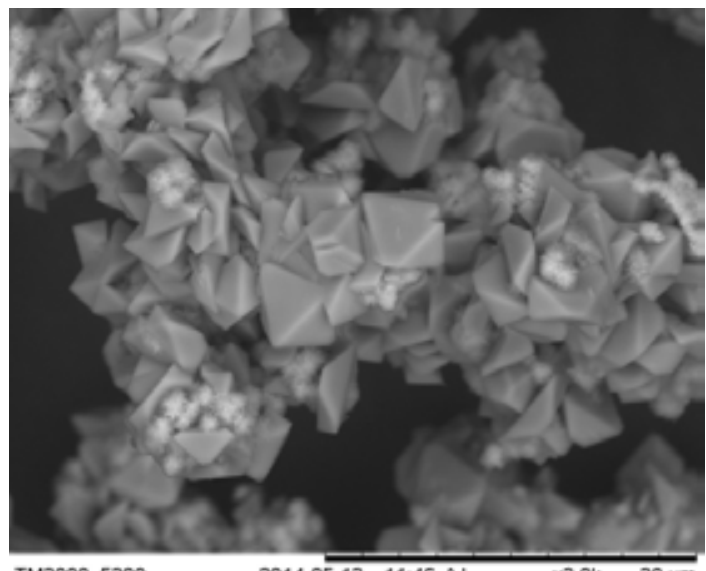

TM3000_5390

2014-05-13 11:46 AL

Рис. 3. Изображение частиц осадка, полученного при 423 К (2 ч)

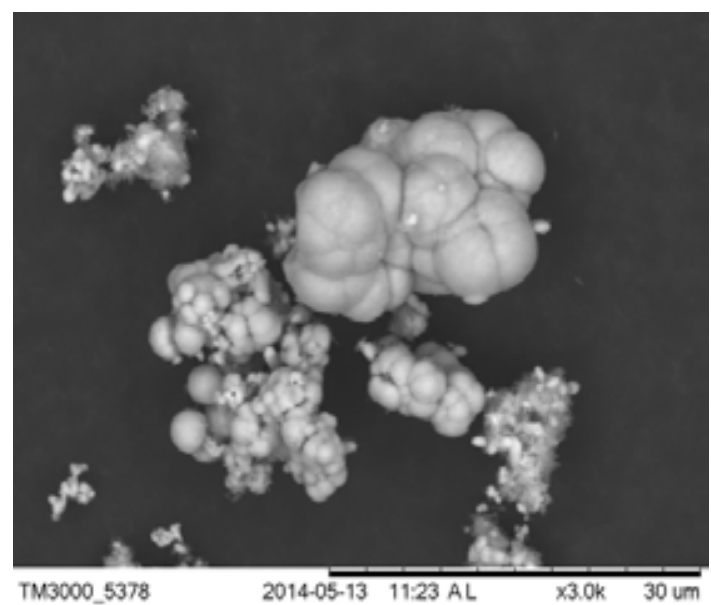

Рис. 4. Изображение частиц осадка, полученного при 453 К (4 ч)

Таблица 3. Результаты экспериментов по осаждению родия и иридия

\begin{tabular}{|c|c|c|c|}
\hline \multicolumn{4}{|c|}{ Осаждение сульфитом натрия при 423 К } \\
\hline \multirow{2}{*}{$\begin{array}{l}\text { Концентрация } \\
\text { осадителя, г/л }\end{array}$} & \multirow{2}{*}{ Время, ч } & \multicolumn{2}{|c|}{ Осаждение, \% } \\
\hline & & иридий & родий \\
\hline 13,4 & 1 & 5 & 40 \\
\hline 55,5 & 1 & 15 & 52 \\
\hline \multicolumn{4}{|c|}{ Осаждение сульфитом натрия при 453 К } \\
\hline \multirow{2}{*}{$\begin{array}{c}\text { Концентрация } \\
\text { осадителя, г/л }\end{array}$} & \multirow{2}{*}{ Время, ч } & \multicolumn{2}{|c|}{ Осаждение, \% } \\
\hline & & иридий & родий \\
\hline 25,5 & 4 & 20 & 66,7 \\
\hline \multicolumn{4}{|c|}{ Осаждение тиосульфатом натрия при 453 К } \\
\hline \multirow{2}{*}{$\begin{array}{l}\text { Концентрация } \\
\text { осадителя, г/л }\end{array}$} & \multirow{2}{*}{ Время, ч } & \multicolumn{2}{|c|}{ Осаждение, \% } \\
\hline & & иридий & родий \\
\hline 10 & 1 & 5 & 30 \\
\hline 10 & 4 & 40 & 33,3 \\
\hline 12 & 8 & 40 & 33,3 \\
\hline
\end{tabular}

\section{Список литературы}

[1] Коваленко Н.Л., Белоусов О.В., Дорохова Л.И. и др. // ЖНХ. 1995. № 4. С. 678.

[2] Belousov O., Belousova N., Sirotina A. el al // Langmuir. 2011. 18. P. 11697. 